\title{
In the shadow of the lionfish: interspecific association involving red emperor snapper (Lutjanus sebae) in Madagascar
}
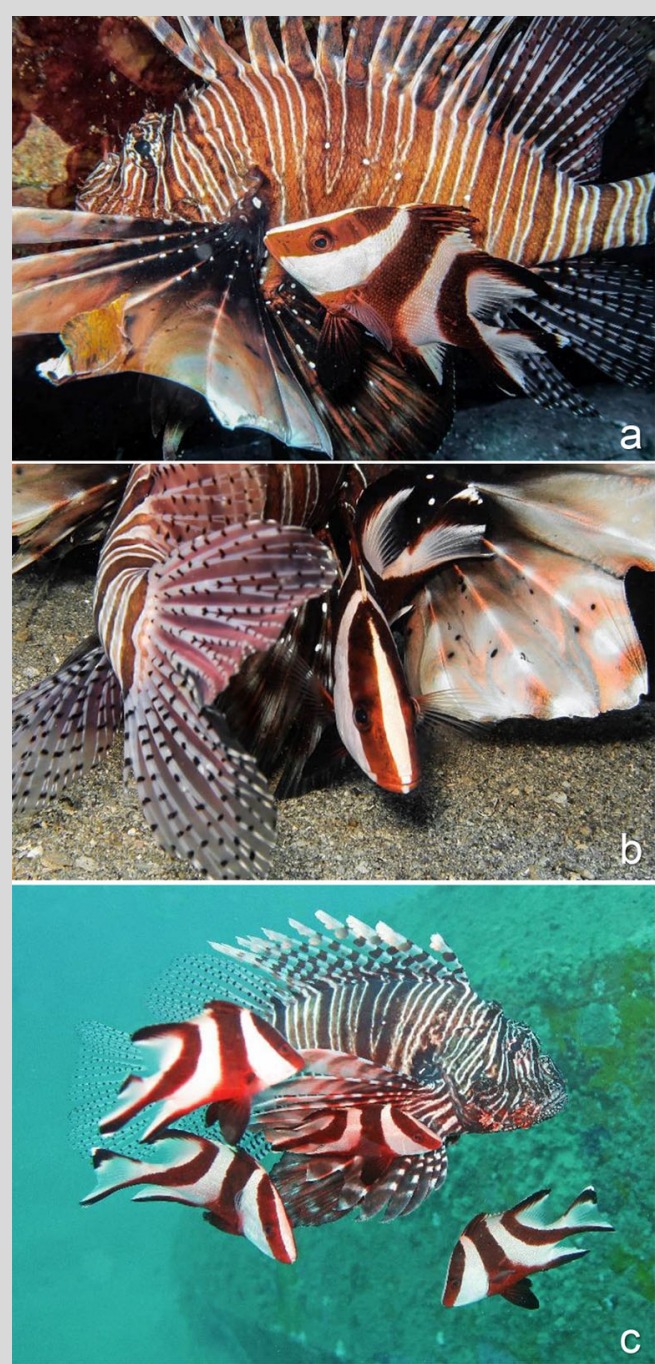

Fig. 1 Juvenile L. sebae next to P. miles (a) and hidden between its fins (b). Several snappers chase a lionfish (c)
During a biodiversity survey on August 2018 in Nosy Be (Madagascar), several individuals of the emperor red snapper Lutjanus sebae were often observed closely associated with the lionfish Pterois miles, which is known to be venomous and to possess disruptive body markings (Fig. 1; Electronic supplementary material Figs. S1-S3 and Video). Since both species share a similar barred light-dark color pattern, the snapper, by swimming next to the lionfish, may prevent visual detection from potential predators through background matching (Fig. 1a). Only juvenile snappers $(<20 \mathrm{~cm}$ long), which usually shelter among sea urchin spines, were observed with the lionfish. In the investigated area, the presence of a sandy substrate without sea urchins and with limited structures, such as corals and other potential refuges, may have led the juveniles $L$. sebae to develop this defensive behavior. In this regard, some snappers were hidden between the fins of the stationary lionfish on the bottom (Fig. 1b). We also observed more than one snapper swimming next to a single lionfish (Fig. 1c).

This interspecific association was previously described only once, by Mahadevan and Nayar (1965) in the Gulf of Mannar (India), and it was mainly attributed to a defensive strategy of $L$. sebae developed thanks to the matching body color of the fishes. Moreover, we hypothesize that $L$. sebae may also be protected by the venomous fin spines of $P$. miles. In addition to protection, juvenile snapper may also benefit from this association in hunting for the preys (Mahadevan and Nayar 1965). However, it remains unknown whether the lionfish benefits from the relationship. For these reasons, further studies are needed to better comprehend the nature of the association, as well as to understand whether this camouflage strategy is widespread throughout the Indo-Pacific and whether similar relationships involving the lionfish have been established in the Caribbean after their introduction.

Acknowledgements The authors thank Barbara Bini (Bibi) and Luca Natali of the Love Bubble Social Diving and Sara Procopio for the logistical support

Compliance with ethical standards

Conflict of interest All authors declare that they have no conflict of interest.

\section{Reference}

Mahadevan S, Nayar KN (1965) Underwater ecological observations in the gulf of Mannar, off Tuticorin-III. On the emperor Bream Lutjanus sebae found with Pterois the scorpion fishes. J Mar Biol Ass India 7:454-455

Electronic supplementary material The online version of this article (https://doi.org/10.1007/s00338-018-01747-8) contains supplementary material, which is available to authorized users.

D. Seveso $(\bowtie) \cdot$ S. Montano $\cdot$ D. Maggioni

MaRHE Center (Marine Research and High Education Centre), Magoodhoo Island, Faafu Atoll, Maldives

e-mail: davide.seveso@unimib.it

Received: 10 October 2018/ Accepted: 20 October 2018/Published online: 31 October 2018

Coral Reefs (2018) 37:1181

(C) Springer-Verlag GmbH Germany, part of Springer Nature 2018

https://doi.org/10.1007/s00338-018-01747-8 